IZA DP No. 10216

Trajectories of Neighborhood Change: Spatial Patterns of Increasing Ethnic Diversity

Merle Zwiers

Maarten Van Ham

David Manley

September 2016 


\title{
Trajectories of Neighborhood Change: Spatial Patterns of Increasing Ethnic Diversity
}

\author{
Merle Zwiers \\ Delft University of Technology
}

Maarten Van Ham

Delft University of Technology and IZA

David Manley

University of Bristol

\section{Discussion Paper No. 10216 \\ September 2016}

\author{
IZA \\ P.O. Box 7240 \\ 53072 Bonn \\ Germany \\ Phone: +49-228-3894-0 \\ Fax: +49-228-3894-180 \\ E-mail: iza@iza.org
}

Any opinions expressed here are those of the author(s) and not those of IZA. Research published in this series may include views on policy, but the institute itself takes no institutional policy positions. The IZA research network is committed to the IZA Guiding Principles of Research Integrity.

The Institute for the Study of Labor (IZA) in Bonn is a local and virtual international research center and a place of communication between science, politics and business. IZA is an independent nonprofit organization supported by Deutsche Post Foundation. The center is associated with the University of Bonn and offers a stimulating research environment through its international network, workshops and conferences, data service, project support, research visits and doctoral program. IZA engages in (i) original and internationally competitive research in all fields of labor economics, (ii) development of policy concepts, and (iii) dissemination of research results and concepts to the interested public.

IZA Discussion Papers often represent preliminary work and are circulated to encourage discussion. Citation of such a paper should account for its provisional character. A revised version may be available directly from the author. 


\title{
ABSTRACT \\ Trajectories of Neighborhood Change: Spatial Patterns of Increasing Ethnic Diversity
}

\begin{abstract}
Western cities are increasingly ethnically diverse and in most cities the share of ethnic minorities is growing. Studies analyzing changing ethnic geographies often limit their analysis to changes in ethnic concentrations in neighborhoods between two points in time. Such a static approach limits our understanding of pathways of ethnic neighborhood change, and of the underlying factors contributing to change. This paper analyzes full trajectories of neighborhood change in the four largest cities in the Netherlands between 1999 and 2013. Our modelling strategy categorizes neighborhoods based on their unique growth trajectories of the ethnic population composition, providing a longitudinal view of ethnic segregation. Our results show that the ethnic composition in neighborhoods remains relatively stable over time. We find evidence for a slow trend towards deconcentration of ethnic minorities and increased (spatial) population mixing in most neighborhoods. We show how residential mobility decreases segregation, while natural population growth tends to reinforce segregation. While the ethnic minority presence in cities grows, there is a substantial share of neighborhoods which can be identified as white citadels; characterized by a stable large native population, with high incomes and high house values. These neighborhoods seem to be inaccessible to ethnic minorities, which illustrates the spatial manifestation of exclusionary elitism in increasingly ethnically diverse cities.
\end{abstract}

JEL Classification: J15, O18, R23

Keywords: ethnic segregation, neighborhood trajectories, population dynamics, latent class growth modelling, longitudinal study

Corresponding author:

Merle Zwiers

OTB - Research for the Built Environment

Faculty of Architecture and the Built Environment

Delft University of Technology

PO Box 5030

2600 GA Delft

The Netherlands

E-mail: m.d.zwiers@tudelft.nl 


\section{Introduction}

The share of ethnic minority residents has been increasing in many major European cities during the past two decades and these cities are experiencing increasing ethnic diversity (Vertovic 2007). For example: In 1999, non-western ethnic minorities comprised 17.1\% of the Dutch population. By 2015, the share of ethnic minorities increased to $21.7 \%$, which, in absolute numbers, means that the number of ethnic minorities in the Netherlands has increased by 1 million in 16 years (Statistics Netherlands 2016). Members of ethnic minorities are attracted to large cities because of the services and the availability of affordable housing (cf. Borjas 1999) and the presence of immigrant networks (Logan et al. 2002). Studies on ethnic segregation have focused on the question of how ethnic minorities are sorting into different neighborhoods in these cities and to what extent they live together or apart from the native population (e.g. Bolt and Van Kempen 2010; Johnston et al. 2009, 2010; Poulsen et al. 2011). Segregation can be viewed as both a condition of neighborhoods and cities at a certain point in time, and a dynamic process that develops through time without a specific end point (Johnston et al. 2010). Only a relatively small number studies have focused on the latter.

There are two main explanations suggested as the main causes of segregation processes. The first lies in residential mobility (e.g. Bolt and Van Kempen 2010). The selective moving behavior of different ethnic groups can affect segregation in different ways. Studies on 'white flight' have shown that ethnic heterogeneity in neighborhoods stimulates the out-mobility of the native (majority) population to more 'white' neighborhoods (e.g. Clark and Coulter 2015; Kaufmann and Harris 2015; Sampson and Sharkey 2008). 'White avoidance' theories, however, argue that the native population avoids ethnically diverse areas in the first place (Clark 1992; Quillian 2002). In both cases, the moving behavior of the native population increases ethnic segregation. With regards to the residential mobility behavior of ethnic minorities, studies on 'spatial assimilation' have argued that as ethnic minorities become more assimilated into the host society over time, they tend to move away from concentration areas developing similar residential mobility patterns as the native population (Bolt and Van Kempen 2010; Sabater 2010; Simpson and Finney 2009; Simpson et al. 2008; Tammaru and Kontuly 2011). However, other results indicate that ethnic segregation is a persistent feature of contemporary cities as ethnic minorities are less likely to leave and more likely to move into ethnically concentrated neighborhoods (Bolt and Van Kempen 2010; Clark and Ledwith 2007; Doff 2010; Feijten and Van Ham 2009; South and Crowder 1998a; Van Ham and Feijten 2008), as a result of a lack of financial resources (Clark and Ledwith 2007), institutional constraints (Galster 1999; Musterd and de Winter 1998), or specific ethnic preferences (Bolt et al. 2008).

A small body of research offers the second explanation and has argued that the effects of residential mobility on segregation should also be understood in relation to demographic changes (Finney and Simpson 2009; Simpson and Finney 2009; Simpson 2004, 2007). Demographic events such as birth and deaths can influence patterns of segregation in different ways. The relatively young age structure of many migrants often implies higher fertility rates when compared with the majority population (Finney and Simpson 2009). When ethnic minorities have disproportionally more children than natives, levels of segregation might increase (Simpson and Finney 2009) irrespective of mobility patterns. Similarly, higher mortality rates among the native population as a result of ageing might lead to high natural decline among natives, thereby increasing levels of ethnic segregation (Finney and Simpson 2009). Whilst these explanations offer competing processes in the development of segregation it is likely that that ethnic segregation is a dynamic process, and is the result of both residential sorting processes and demographic shifts.

In the context of growing ethnic diversity in many cities, it is an important question to what extent this growth is evenly distributed over neighborhoods within these cities. Are there particular neighborhoods that experience more than average increases in their share of ethnic minorities, and if 
so, is this increase driven by selective sorting processes or natural growth? Or are ethnic minorities increasingly integrated, showing more variation in their spatial distribution over time? The present study aims to answer these questions by analyzing full trajectories of neighborhood change in the four largest cities in the Netherlands between 1999 and 2013. We employ a latent class growth model to categorize neighborhoods based on their unique growth trajectories of the ethnic population composition over time. This modelling strategy offers an empirical contribution to segregation research by analyzing distinctly different longitudinal patterns of ethnic neighborhood change, contributing to our understanding of diverging processes of ethnic segregation over time. Theoretically, this paper bridges two important fields of literature on the drivers behind ethnic segregation: residential mobility and natural growth. By integrating these theories, we seek to better understand the relative impact of both mechanisms on various levels of ethnic segregation.

\section{The Spatial Distribution of Ethnic Minorities}

Many studies on the spatial distribution of ethnic groups in urban areas have focused on the clustering of ethnic minorities in particular (often disadvantaged) neighborhoods and the potential hampering effects of segregation on social integration, mobility, and interethnic contact, posing a threat to inclusive diverse societies (Kaplan and Douzet 2011; Monkkonen and Zhang 2013; Van Ham and Tammaru 2016). Previous studies on ethnic segregation have used single-number indices to express the level of uneven spatial distribution of ethnic groups, or their isolation, centralization, concentration or clustering (Massey and Denton 1988; Poulsen et al. 2011). Other studies have created typologies of neighborhoods ranging from ghetto's or enclaves to white citadels to analyze different forms of spatial concentrations of ethnic groups (Marcuse 1997; Poulsen et al. 2001). Most of these studies focus on the degree of segregation at one point in time; analyzing segregation as a condition of cities and neighborhoods.

A number of studies have focused on residential mobility patterns in relation to ethnic segregation. The residential sorting of ethnic minorities can mostly be explained by the availability of affordable housing and the presence of ethnic networks. Researchers have argued that ethnic minorities tend to move to ethnically dense neighborhoods after recent immigration, because of the benefits in terms of social networks and support from other co-ethnics (Dunn 1998; Peleman 2002). However, over time, ethnic minorities tend to move away from concentration areas showing similar residential mobility patterns as the native population (Bolt and Van Kempen 2010; Sabater 2010; Simpson and Finney 2009; Simpson et al. 2008; Tammaru and Kontuly 2011). This process of 'spatial assimilation' is arguably the result of increasing socio-economic and cultural assimilation (Alba and Logan 1993; Fong and Wilkes 1999; South and Crowder 1998b). Indeed, empirical research has shown that ethnic minorities display processes of suburbanization (Hussain and Stillwell 2008; Sabater 2010; Simpson et al. 2008) and are more likely to move away from concentration areas when their socioeconomic situation improves (Bolt and Van Kempen 2010; South and Crowder 1998b). However, several of these studies have come to the same conclusion: after controlling for socioeconomic differences, ethnic minorities continue to be more likely to move into concentration neighborhoods (Bolt and Van Kempen 2010; South and Crowder 1998b). This finding is often explained by discrimination on the housing market (Aalbers 2013; Galster 1999; Massey and Denton 1993; Manley and Van Ham 2011; Musterd et al. 1998), or own-group preferences (Bolt et al. 2008).

The residential mobility behavior of the native population also plays a role in the process of place stratification. Research on 'White flight' has argued that natives tend to move away from ethnic minority neighborhoods (Crowder and South 2008; Galster 1990; Massey and Denton 1993). Studies on 'White avoidance' have shown that natives tend to avoid minority populated neighborhoods (Farley 
et al. 1994; South and Crowder 1998b). Both mechanisms have been found to be important explanations for the persistence of high levels of ethnic segregation. The concepts of 'White flight' and 'White avoidance' originate from US research and few studies have used these concepts to analyze residential segregation in the European context (Brama 2006). In Europe, 'White flight' or 'White avoidance' is implicitly equated with socioeconomic flight or avoidance, showing that highincome natives tend to move away from, or avoid, immigrant areas (cf. Brama 2006; Erdosi et al. 2003; Mezetti et al. 2003). These processes have led to the development of 'white citadels' (Marcuse 1997): relatively exclusive residential areas where the native population lives isolated from the rest of the (immigrant) population (Poulsen et al. 2011).

An small body of research suggests that the effects of residential mobility on segregation need to be understood in relation to demographic developments (e.g. Simpson et al. 2008). Fertility rates are generally higher among immigrants, because of their relatively young age structure. In particular, the fact that ethnic minorities tend to have more children than natives combined with a native population who are ageing means that ethnic groups have a relatively high rate of natural increase (Simpson and Finney 2009). Processes of family formation in the years after immigration can therefore lead to increasing ethnic concentrations in particular areas (Finney and Simpson 2009). However, over time, fertility rates are likely to decline as a greater spread of family stages can be expected among next generations (Simpson et al. 2008).

The evidence thus far presents competing processes in the development of segregation. While the selective sorting behavior of the native population, together with high fertility rates among ethnic minorities, could raise segregation; the spatial assimilation of ethnic minorities as a result of their adoption of majority group preferences would lower segregation. Although it can reasonably be assumed that segregation is a dynamic process that is the result of both selective mobility behavior and demographic events, it remains unclear how different residential and/or demographic processes, occurring simultaneously within cities, affect segregation.

Most studies investigating ethnic segregation have either focused on (1) the degree of segregation at one point in time, or (2) decreasing or increasing levels of segregation between two points in time. Studies in this vein have been limited by the lack of longitudinal studies, failing to consider trajectories of ethnic neighborhood change. As such, our understanding of changing spatial patterns of ethnic population change remains limited (Catney 2015b). By analyzing full neighborhood trajectories over time, the present study aims to provide a longitudinal view on segregation by identifying distinct spatial trajectories of ethnic population change.

\section{Data and Methods}

This study uses longitudinal register data from the System of Social statistical Datasets (SSD) from Statistics Netherlands providing data on the full Dutch population from 1999 to 2013 . We focus on the share of ethnic minorities in 500 by 500 meter grids in the four largest cities in the Netherlands: Amsterdam, Rotterdam, Utrecht and the Hague. We concentrate on the four largest non-western migrant groups in the Netherlands: the Moroccans, Turks, Surinamese and Antillians. Moroccans and Turks immigrated to the Netherlands in the 1970s, mainly due to labor migration, while the postcolonial migration of the Surinamese and Antillians occurred in the 1980s and 1990s. In the Dutch context, a person is considered to belong to an ethnic minority when he/she is born abroad or when one of his/her parents is born abroad (Statistics Netherlands, 2016). We focus on the share of nonwestern ethnic minorities relative to the total population in a neighborhood. Residential mobility is measured by net migration rates. Natural growth is defined as the number of births minus the number of deaths. Additional information on the share of households at risk of poverty (household income 
$60 \%$ below the median), average household income and average house prices has been added to the dataset. Our units of analysis are the 500 by 500 meter grids in the four largest cities, which leads to a total sample size of 1496 grids. Grids with fewer than 10 residents have been excluded from the analyses for privacy reasons.

To analyze the neighborhood trajectories of the ethnic composition over time, we employ a latent class growth model (LGCM). Such a model allows for the categorization of neighborhoods based on their unique growth trajectories of the ethnic population composition. LGCMs enable the analysis of longitudinal data where there may be qualitatively different trajectories over time that are not identifiable ex ante (Nagin 2005). LCGMs are finite mixture models that utilize a multinomial modelling strategy (Jones and Nagin 2013). Where growth curve models assume that all individual units of analysis are drawn from the same population with the same growth trajectory over time, LGCMs are based on the idea that individual units belong to different subpopulations (latent classes) that each have a unique growth trajectory (Nagin 2005; Perelli-Harris and Lyons-Amos 2013). The main assumption is that the outcome variable is conditional on time and that there are a finite number of different outcome trajectories of unknown order (Jones and Nagin 2013).

Because of the large number of zeros in the data, a zero-inflated Poisson model provides the most appropriate specification. Model selection is determined in two stages. We first assessed the optimal number of classes by comparing the Akaike Information Criterion (AIC), the Bayesian Information Criterion (BIC) and the Sample-Size Adjusted Bayesian Information Criterion (SSBIC). Model fit is compared after adding a trajectory in a stepwise approach. The model with the lowest fit statistics is preferred (Nylund et al. 2007). Although the BIC has been found to be a good indicator for determining the number of classes when the sample size is large enough $(\mathrm{N}>1000)$ (Nylund et al. 2007; Roeder and Wasserman 1997; Yang 2006) ${ }^{1}$, model convergence is a well-known problem with latent class growth analysis (Jung and Wickrama 2008). An additional statistic to analyze model fit is the average posterior probability (AvePP). The AvePP reflects the average probability that individual units belong to a trajectory group. A high AvePP implies a high probability of group membership (Nagin 2005). We have compared the BIC and AvePP for multiple models, ranging from models with three trajectory groups to models with eight trajectory groups (see Table 4). We have selected a sixclass model. Although the seven- and eight-group models have lower BIC values and high AvePP's, these additional trajectories do not substantially differ from those in the six-group model. When it is difficult to clearly identify an optimal number of groups, the most parsimonious model that provides distinctively different trajectory groups should be selected (Nagin 2005; see also Damaske and Frech 2016).

Next, the shape of each of the six trajectories is estimated by specifying the order of the polynomial (Nagin 2005). ${ }^{2}$ We estimated our model in Stata 14 using the package "traj" (Jones and Nagin 2013). We have checked the robustness of our findings by conducting the analyses on different subsets of the data and by reproducing our analyses in Mplus version 6.0.0.1. All analyses yield similar results.

To explore the role of population dynamics in each of the identified trajectories, we have created a series of profile plots. We visualize the net migration rates and natural growth rates for each of the trajectories. In addition, we have created maps of the trajectories for each of the four cities. To analyze the degree of spatial clustering of the trajectories, the Getis-Ord Gi* has been calculated for each of the four cities.

\footnotetext{
${ }^{1}$ Some researchers favor the use of the Bootstrap Likelihood Ratio Test (BLRT) for identifying the optimal number of classes (Nylund et al. 2007), however, this test is computationally too intensive.

${ }^{2}$ The final model will have lower BIC values as a result of specifying the shape of the polynomial.
} 


\section{Results}

In 1999, the number of ethnic minorities in the four largest Dutch cities was 430,616, comprising $21,2 \%$ of the total population. In 2013 , the number of ethnic minorities rose to 536,307 , comprising $23,9 \%$ of the total population. In absolute terms, the rise in the number of ethnic minorities reflects a $24,8 \%$ increase (authors own calculations). Despite this increase, we generally find stable neighborhood trajectories in terms of the ethnic population composition over time. Table 1 presents the maximum likelihood estimates from the Zero-Inflated Poisson Latent Class Growth Model. The six trajectories are plotted in Fig. 1.

\section{[insert Table 1 about here]}

[insert Fig. 1 about here]

The first trajectory group accounts for $12.7 \%$ of the neighborhoods in the four largest cities and is characterized by an intercept-only polynomial $(b=-0.789, \mathrm{p}<0.0001)$. This means that, unlike the other trajectory groups, there has been no change in the share of ethnic minorities in this group of neighborhoods over the entire 15-year observation period. Despite the general increase in the number of ethnic minorities in these four cities, this first trajectory group consists of neighborhoods with hardly any ethnic minorities. The second trajectory group is estimated to account for $24.2 \%$ of the neighborhoods and follows a linear trajectory of an increasing share of ethnic minorities, albeit slightly $(b=0.036, p<0.0001)$. The third trajectory group shows a similar increasing linear trajectory ( $b=0.043, p<0.0001$ ), comprising $21.0 \%$ of the neighborhoods. More than $50 \%$ of the neighborhoods in the four largest Dutch cities are characterized by low shares of ethnic minorities, although approximately $40 \%$ of these neighborhoods have experienced slight increases in the share of ethnic minorities over time. The fourth trajectory group accounts for $18.7 \%$ of the neighborhoods and is quadratic-shaped $(b=-0.002, p<0.0001)$. The fifth and sixth trajectory groups show similar quadratic trajectories $(b=-0.002, p<0.0001$ and $b=-0.001, p<0.0001)$, accounting for $15.1 \%$ and $8.3 \%$ of all neighborhoods, respectively. The share of ethnic minorities is the highest in this latter group of neighborhoods, illustrating that $8.3 \%$ of all neighborhoods in the four largest Dutch cities are characterized by concentrations of ethnic minorities that are close to $60 \%$. The negative coefficients for these three trajectory groups, however, illustrate monotonically decreasing trends, although at different time points (see Fig. 1). This means that these neighborhoods originally experienced an increase in the share of ethnic minorities, but that they have seen a decrease in the share of ethnic minorities towards the end of our observation period. This trend appears to be most advanced in the sixth trajectory group. Substantively, this points to different trends occurring within the same cities at different time points.

Table 2 shows the average characteristics of the neighborhoods in each of the six classes in 2013. The first trajectory group is characterized by very few ethnic minorities and a high share of native Dutch $(82.7 \%)$. Despite a high average household income of 73,202 euros a year, $19.5 \%$ of the households in these neighborhoods are at risk of poverty. This might be explained by the Dutch tradition of social mixing, where social housing is located in a variety of different neighborhoods (Van Kempen and Priemus 2002). The average housing value in the first trajectory group lies at 502,699 euros. As such, these neighborhoods can be seen as 'white citadels' (Marcuse 1997): neighborhoods that are populated by a large native majority and are characterized by above average incomes and house values.

Each subsequent trajectory group shows an increase in the share of ethnic minorities and a decrease in the share of native Dutch. Similarly, the average household income and the average 
housing value decreases with each trajectory, while the share of households at risk of poverty increases. Neighborhoods in the sixth trajectory with the highest share of ethnic minorities are characterized by a $53.9 \%$ minority population in $2013.21 .9 \%$ of the population in these neighborhoods are native Dutch. The average household income lies at 31,037 euros a year which is less than half of the average income in the first trajectory group. The average house value of 139,770 is almost five times lower than the average house values in the first trajectory group. The share of households at risk of poverty is $44.5 \%$ in these neighborhoods. This group of neighborhoods can be seen as ethnic concentration neighborhoods characterized by relative disadvantage. These findings confirm the assumption that the spatial patterning of ethnic minorities strongly related to income.

[insert Table 2 about here]

To understand how these patterns of ethnic neighborhood change can be explained, we analyze the role of residential mobility and natural change. Fig. 2 shows the mean net migration rates of ethnic minorities in each of the six trajectories. The plot shows that there is no ethnic migration in the first trajectory group. This finding seems to suggest that these white citadels are exclusionary spaces that are inaccessible to ethnic minorities.

The second and third trajectory group have experienced positive net migration over our 15year observation period. These positive migration rates seem to be more or less stable over time. The negative quadratic-shaped trend for the fourth, fifth and sixth trajectory group can be explained by the declining migration rates of ethnic minorities. The negative net migration rates of ethnic minorities in these trajectory groups illustrates that there are more ethnic minorities moving out of these neighborhoods than in. This trend is most pronounced in the fifth and sixth trajectory group, meaning that the most ethnically concentrated neighborhoods show a decrease in the share of ethnic minorities as a result of ethnic out-mobility.

[insert Fig. 2 about here]

Fig. 3 illustrates the role of natural population change in each of the trajectories. The plot first of all shows that fertility rates among ethnic minorities have declined over time. This makes sense, as the immigrant population matures over time, fertility rates will decline (cf. Simpson et al. 2008). The plot shows that the number of ethnic minority children born has remained stable in the first three trajectory groups; where there is no natural growth in the first trajectory group and general stable natural growth in the second and third trajectory group. The last three trajectory groups have seen a decrease in natural growth over time, yet there is still positive natural change, meaning that the number of births still exceed the number of deaths among ethnic minorities in these neighborhoods.

[insert Fig. 3 about here]

Fig. 2 suggests that selective mobility is an important driver behind changing ethnic residential patterns. Many ethnic minorities are moving out of the strongest concentration neighborhoods and are moving into more ethnically mixed areas. However, at the same time, Fig. 3 shows that positive natural growth tends to reinforce existing patterns of ethnic segregation in the strongest concentration neighborhoods. The combination of natural growth and ethnic mobility in neighborhoods in trajectory group two and three seem to explain the slow growth in ethnic diversity.

Fig. 4 to 7 show maps of the spatial distribution of the six trajectories in each of the four cities using 500 by 500 meter grid cells. 
[insert Fig. 4, 5, 6, 7 about here]

The maps seem to suggest that neighborhoods that experience the same trajectory over time are generally clustered together. To analyze the degree of spatial clustering, the Getis-Ord Gi* has been calculated for each of the four cities (see Table 3).

[insert Table 3 about here]

We find a significant degree of spatial clustering in each of the four cities. Additional hotspot analyses have shown that trajectory groups 1 and 2 and trajectory groups 5 and 6 tend to be specifically clustered together (maps available upon request). Trajectory group 5 and 6 are comprised of neighborhoods with the highest shares of ethnic minorities which tend to be located on the edges of all four cities. Many of these areas are postwar neighborhoods and are characterized by high shares of low-quality (social rented) housing. This finding is in line with previous studies on segregation in the Netherlands and shows considerable overlap with income segregation (Hochstenbach and Van Gent 2015; Van Gent 2013; Zwiers et al. 2016). Neighborhoods in trajectory group 1, the white citadels, seem to be clustered together with neighborhoods in trajectory group 2 . These white citadels appear to be small islands in expensive parts of each city, such as a few neighborhoods in the southern part of Amsterdam, and coastal neighborhoods in the Hague. Neighborhoods that have experienced slight increases in the share of ethnic minorities (trajectory group 3 and 4) are much more scattered across each cities. These findings seem to suggest that spatial mixing occurs more or less randomly across neighborhoods, while neighborhoods with high shares of native Dutch and neighborhoods with high shares of ethnic minorities show much more spatial concentration.

\section{Discussion and Conclusion}

This paper has argued that segregation is both a condition of cities and neighborhoods and a process that develops over time. Although many studies have investigated changes in segregation, very few have actually investigated ethnic neighborhood change over a longer period of time and with a high temporal resolution of data presented here. In light of increasing ethnic diversity in most cities, it is especially important to investigate how the increasing diversity is being expressed spatially. The present study has investigated full trajectories of neighborhood change in the four largest cities in the Netherlands between 1999 and 2013 by using latent class growth models. Our modelling strategy allowed us to identify neighborhoods which follow similar trajectories of ethnic neighborhood change over time. We identified six distinctly different neighborhood trajectories over time, each showing a different trend of change. These trends were developing at a slow pace, showing relative stability over a 15-year period. These slow developments are in line with previous studies that argue that neighborhoods are rather slothful and that significant changes take long to take effect (Meen et al. 2013; Tunstall 2016; Zwiers et al. 2016).

Our approach has yielded various interesting findings. The first is that we have identified a group of neighborhoods in the four largest cities in the Netherlands with hardly any ethnic minorities over the entire observation period. Neighborhoods in the first trajectory group are characterized by a high average income, a high average housing value and a high share of native Dutch. As such, these neighborhoods can be labelled 'white citadels': "A citadel is a spatially concentrated area in which members of a particular population group, defined by its position of superiority, in power, in wealth, or status, in relation to its neighbors, congregate as a means of protecting or enhancing that position." (Marcuse 1997, p. 247). This exclusive separation of the native population from ethnic minorities has 
been found in other studies as well (Johnston et al. 2003, 2009; Marcuse 1997; Marcuse and Van Kempen 2000a; Poulsen et al. 2002). These white citadels tend to be clustered together with other expensive neighborhoods and seem to function as exclusionary zones or gated communities (Marcuse 1997). The question however remains to what extent this exclusionary elitism in these increasingly ethnically diverse cities is the result of 'White flight' or 'White avoidance' and to what extent these neighborhoods are accessible to other groups. The present study has focused on the residential patterns of ethnic minorities and have found no ethnic migration into or out of these white citadels. Future research could provide more insight in the residential patterns of these native elites and analyze to what extent these white citadels are the result of native self-segregation.

A second finding is that the increase in the share of ethnic minorities in the four largest cities is largely absorbed by neighborhoods with low levels of ethnic minority populations. These trajectory groups (the second and the third) are characterized by relatively low shares of ethnic minorities, but show a slow trend towards a linear increase. Other studies also report similar patterns of spatial mixing in previously majority-dense neighborhoods (Catney, 2015a, b; Johnston et al. 2015). Our results demonstrate that this trend can likely be explained by a combination of positive net migration and natural growth. These neighborhoods can be characterized as relatively high-quality neighborhoods with high average incomes and above average house values. It is possible that higher educated young ethnic couples move to these neighborhoods to start a family. However, it remains unclear to what extent increases in the share of ethnic minorities in these neighborhoods are the result of the socioeconomic assimilation of the next generation of ethnic minorities or changes on the housing market which offer opportunities for ethnic minorities, or both. As processes of neighborhood change are the consequences of mobility decisions, processes of neighborhood upgrading or downgrading can have important effects on the spatial distribution of different residential groups (Pfeiffer and Molina 2013).

A third finding is that the share of ethnic minorities in those neighborhoods with already high shares is actually decreasing (the fourth, fifth and sixth trajectory groups). This trend is most advanced in the neighborhoods with the highest share of ethnic minorities (the fifth and sixth trajectory group). Ethnic minorities are the majority group in these neighborhoods which are characterized by a low average income, a low average housing value and a low share of native Dutch. We find that the deconcentrating trend can be explained by negative migration rates. However, although ethnic minorities are increasingly moving away from these concentration neighborhoods, positive natural growth seems to slow this trend down. These findings seem to be in line with previous studies that argue that as ethnic minorities become more assimilated in society, they tend to move away from concentration neighborhoods mirroring the residential mobility patterns of the native population. In addition, we find that as ethnic minorities age over time and the number of children born decreases, the role of natural growth in processes of segregation seems to decrease (cf. Simpson and Finney 2009), but continues to play a role in maintaining existing levels of segregation.

Our results confirm that there is a strong relation between the spatial patterning of ethnic minorities and socioeconomic status. Neighborhoods with high shares of ethnic minorities are generally characterized by lower incomes, lower housing values and more households at risk of poverty, while neighborhoods with hardly any ethnic minorities are characterized by relative advantage. The fact that these latter group of neighborhoods appear to be inaccessible to ethnic minorities raises questions about the exclusion of certain groups in particular parts of cities. Although we find a trend towards ethnic deconcentration and increased spatial mixing in different parts of the city, we find significant spatial clustering of disadvantaged, ethnically concentrated neighborhoods and relatively expensive, native Dutch neighborhoods. It has indeed been argued that mixing may be restricted to certain neighborhoods only: extreme segregation appears to be a persistent feature of the bottom and top ends of the income distribution (Marcuse and Van Kempen 2000b; see also Tammaru 
et al. 2016). Future research should therefore analyze how these trends develop in the future and focus on the spatial trajectories of the next generations of ethnic minorities.

\section{Acknowledgements}

The research leading to these results has received funding from the European Research Council under the European Union's Seventh Framework Program (FP/2007-2013) / ERC Grant Agreement n. 615159 (ERC Consolidator Grant DEPRIVEDHOODS, Socio-spatial inequality, deprived neighbourhoods, and neighbourhood effects) and from the Marie Curie program under the European Union's Seventh Framework Program (FP/2007-2013) / Career Integration Grant n. PCIG10-GA2011-303728 (CIG Grant NBHCHOICE, Neighbourhood choice, neighbourhood sorting, and neighbourhood effects). The authors would like to thank dr. Bobby Jones from the University of Pittsburgh Medical Center for his useful comments and suggestions throughout the modelling process.

\section{REFERENCES}

Aalbers, M. B. (2013). How do mortgage lenders influence neighbourhood dynamics? Redlining and predatory lending. In M. Van Ham, D. Manley, N. Bailey, L. Simpson \& D. MacLennan (Eds.) Understanding neighbourhood dynamics: New insights for neighbourhood effects research (pp. 63-85). Dordrecht: Springer Netherlands.

Alba, R.D., \& Logan, J.R. (1993). Minority proximity to whites in suburbs: An individual-level analysis of segregation. American Journal of Sociology, 98, 1388-1427.

Bailey, N. (2012). How spatial segregation changes over time: Sorting out the sorting processes. Environment and Planning A, 44 (3), 705-722.

Bolt, G., Van Kempen, R., \& Van Ham, M. (2008) Minority ethnic groups in the Dutch housing market: Spatial segregation, relocation dynamics and housing policy. Urban Studies, 45, 1359-138.

Bolt, G., \& Van Kempen, R. (2010). Ethnic segregation and residential mobility: Relocations of minority ethnic groups in the Netherlands. Journal of Ethnic and Migration Studies, 36 (2), 333-354.

Borjas, G. J. (1999). The economic analysis of immigration. Handbook of Labor Economics, 3, $1697-$ 1760 .

Brama, A. (2006). 'White flight'? The production and reproduction of immigrant concentration areas in Swedish cities, 1990-2000. Urban Studies, 43 (7), 1127-1146.

Catney, G. (2015a). The changing geographies of ethnic diversity in England and Wales, 1991-2011. Population, Space and Place, DOI: 10.1002/psp.1954

Catney, G. (2015b). Towards an enhanced understanding of ethnic group geographies using measures of clustering and unevenness. The Geographical Journal, DOI: 10.1111/geoj.12162

Clark, W. A. (1992). Residential preferences and residential choices in a multiethnic context, Demography, 29, 1-19.

Clark, W. A., \& Coulter, R. (2015). Who Wants to Move? The Role of Neighbourhood Change. Environment and Planning A, 47(12), 2683-2709.

Clark, W. A., \& Ledwith, V. (2007). How much does income matter in neighborhood choice? Population Research and Policy Review, 26 (2), 145-161.

Crowder, K., \& South, S.J. (2008). Spatial dynamics of White flight: the effects of local and extralocal racial conditions on neighborhood out-migration. American Sociological Review, 73, 792-812.

Damaske, S., \& Frech, A. (2016). Women's work pathways across the life course. Demography, DOI: 10.1007/s13524-016-0464-z.

Doff, W. (2010). Puzzling neighbourhood effects: Spatial selection, ethnic concentration and neighbourhood impacts. Delft: IOS Press.

Dunn, K. (1998). Rethinking ethnic concentration: the case of Cabramatta, Sydney. Urban Studies, 35 (3), 503-370. 
Erdosi, S., Geroha, Z., Teller, N., \& Tosics, I. (2003). Large housing estates in Hungary: Overview of developments and problems in Budapest and Nyiregyhaza. Restate Report 2c. Urban and Regional Research Centre, Faculty of Geosciences, University of Utrecht.

Farley, R., Steeh, C., Krysan, M., Jackson, T., \& Reeves, K. (1994). Stereotypes and segregation: Neighborhoods in the Detroit Area. American Journal of Sociology, 100, 750-780.

Feijten P.M., \& Van Ham M. (2009). Neighbourhood change... reason to leave? Urban Studies, 46, 2103-2122.

Finney, N., \& Simpson, L. (2009). Population dynamics: The roles of natural change and migration in producing the ethnic mosaic. Journal of Ethnic and Migration Studies, 35 (9), 1479-1496.

Fong, E., \& Wilkes, R. (1999). The spatial assimilation model reexamined: An assessment by Canadian data. International Migration Review, 33 (3), 594-620.

Galster, G.C. (1990). White flight from racially integrated neighborhoods in the 1970s: the Cleveland Experience. Urban Studies, 27, 385-399.

Galster, G.C. (1999). The evolving challenges of fair housing since 1968: Open housing, integration, and the reduction of ghettoization. Cityscape, 123-138.

Hochstenbach, C., \& Van Gent, W.P.C. (2015). An anatomy of gentrification processes: Variegating causes of neighbourhood change. Environment and Planning A, 47, 1480-1501.

Hussain, S., \& Stillwell, J. (2008). Internal migration of ethnic groups in England and Wales by age and district type. Working Paper 08/3, School of Geography, University of Leeds, Leeds.

Jones, B., \& Nagin, D. (2013). A note on a Stata plugin for estimating group-based trajectory models. Sociological Research Methods, 42, 608-613.

Johnston, R., Poulsen, M., \& Forrest, J. (2003). And did the walls come tumbling down? Ethnic residential segregation in four US metropolitan areas 1980-2000. Urban Geography, 24 (7), 560-581.

Johnston, R., Poulsen, M., \& Forrest, J. (2009). Research note-Measuring ethnic residential segregation: Putting some more geography. Urban Geography, 30 (1), 91-109.

Johnston, R., Poulsen, M., \& Forrest, J. (2010). Moving on from indices, refocusing on mix: On measuring and understanding ethnic patterns of residential segregation. Journal of Ethnic and Migration Studies, 36 (4), 697-706.

Johnston, R., Poulsen, M., \& Forrest, J. (2015). Increasing diversity within increasing diversity: The changing ethnic composition of London's neighbourhoods, 2001-2011. Population, Space and Place, 21 (1), 38-53.

Jung, T., \& Wickrama, K.A.S. (2008). An introduction to latent class growth analysis and growth mixture modeling. Social and Personality Psychology Compass, 2 (1), 302-317.

Kaplan, D. H., \& Douzet, F. (2011). Research in ethnic segregation III: Segregation outcomes. Urban Geography, 32 (4), 589-605.

Kaufmann, E., \& Harris, G. (2015). "White flight" or positive contact? Local diversity and attitudes to immigration in Britain. Comparative Political Studies, 48 (12), 1563-1590.

Logan, J., Zhang, W., \& Alba R. (2002). Immigrant enclaves and ethnic communities in New York and Los Angeles. American Sociological Review, 67, 299-322

Manley, D., \& Van Ham, M. (2011). Choice-based letting, ethnicity and segregation in England, Urban Studies, 48 (14), 3125-3143.

Marcuse, P. (1997). The enclave, the citadel, and the ghetto: What has changed in the post-fordist US city. Urban Affairs Review, 33 (2), 228-264.

Marcuse, P., \& Van Kempen, R. (2000a). Introduction. In: P. Marcuse \& R. Van Kempen (Eds.) Globalizing Cities: A New Spatial Order (pp. 1-21). Oxford, UK: Blackwell.

Marcuse, P., \& Van Kempen, R. (2000b). Conclusion: A changed spatial order. In: P. Marcuse \& R. Van Kempen (Eds.) Globalizing Cities: A New Spatial Order (pp. 249-275). Oxford, UK: Blackwell.

Massey, D. S., \& Denton, N.A. (1988). The dimensions of residential segregation. Social Forces, 67, 281-315. 
Massey, D. S., \& Denton, N. A. (1993). American Apartheid. Cambridge, MA: Harvard University Press.

Meen, G., Nygaard, C., \& Meen, J. (2013). The causes of long-term neighbourhood change. In M. Van Ham, D. Manley, N. Bailey, L. Simpson, \& D. Maclennan (Eds.) Understanding Neighbourhood Dynamics: New Insights for Neighbourhood Effects Research (pp. 43-62). Dordrecht, the Netherlands: Springer.

Mezzetti, P., Mugano, S., \& Zajczyk, F. (2003). Large housing estates in Italy: Overview of developments and problems in Milan. Restate Report 2d, Urban and Regional Research Centre, Faculty of Geosciences, University of Utrecht.

Monkkonen, P., \& Zhang, X. (2014). Innovative measurement of spatial segregation: Comparative evidence from Hong Kong and San Francisco. Regional Science and Urban Economics, 47, 99-111.

Musterd, S., \& de Winter, M. (1998). Conditions for spatial segregation: some European perspectives. International Journal of Urban and Regional Research, 22 (4), 665-673.

Nagin, D. (2005). Group-Based Modeling of Development. Cambridge/London: Harvard University Press.

Nylund, K.L., Asparouhov, T., \& Muthén, B.O. (2007). Deciding on the number of classes in latent class analysis and growth mixture modelling: A Monte Carlo simulation study. Structural Equation Modeling, 14 (4), 535-569.

Peleman, K. (2002). The impact of residential segregation on participation in associations: The case of Moroccan women in Belgium. Urban Studies, 39 (4), 727-747.

Perelli-Harris, B., \& Lyons-Amos, M. (2015). Changes in partnership patterns across the life course: An examination of 14 countries in Europe and the United States. Demographic Research, 33 (6), 1-36.

Pfeiffer, D., \& Molina, E.T. (2013). The trajectory of REOs in Southern California Latino neighborhoods: An uneven geography of recovery. Housing Policy Debate, 23 (1), 81-109.

Poulsen, M., Johnston, R., \& Forrest, J. (2001). Intraurban ethnic enclaves: Introducing a knowledgebased classification method. Environment and Planning A, 33, 2071-2082.

Poulsen, M., Forrest, J., \& Johnston, R. (2002). From modern to postmodern? Contemporary ethnic residential segregation in four US metropolitan areas. Cities, 19 (3), 161-172.

Poulsen, M., Johnston, R., \& Forrest, J. (2011). Using local statistics and neighbourhood classifications to portray ethnic residential segregation: A London example. Environment and Planning B: Planning and Design, 38, 636-658.

Quillian, L. (2002). Why is Black - White residential segregation so persistent? Evidence on three theories from migration data. Social Science Research, 31, 197-202.

Roeder, K., \& Wasserman, L. (1997). Practical Bayesian density estimation using mixtures of normals. Journal of the American Statistical Association, 92, 894-902.

Sabater, A. (2010). Ethnic residential segregation change in England and Wales. In: J. Stillwell \& M. Van Ham (Eds.) Ethnicity and Integration (pp. 47-62). Dordrecht: Springer Netherlands.

Sampson, R. J., \& Sharkey, P. (2008). Neighborhood selection and the social reproduction of concentrated racial inequality. Demography, 45 (1), 1-29.

Simpson, L. (2004). Statistics of racial segregation: Measures, evidence and policy. Urban Studies, 41 (3), 661-681.

Simpson, L. (2007). Ghettos of the mind: The empirical behaviour of indices of segregation and diversity. Journal of the Royal Statistical Society: Series A (Statistics in Society), 170 (2), $405-$ 424.

Simpson, L., Gavalas, V., \& Finney, N. (2008). Population dynamics in ethnically diverse towns: The long-term implications of immigration. Urban Studies, 45 (1), 163-183. 
Simpson, L., \& Finney, N. (2009). Spatial patterns of internal migration: Evidence for ethnic groups in Britain. Population, Space and Place, 15 (1), 37-56.

South, S.J., \& Crowder, K.D. (1998a). Housing discrimination and residential mobility: Impacts for Blacks and Whites. Population Research and Policy Review, 17, 369-387.

South, S.J., \& Crowder, K.D. (1998b). Leaving the 'hood: Residential mobility between Black, White, and integrated neighborhoods, American Sociological Review, 63 (1), 17-26.

Statistics Netherlands (2016). Bevolking; kerncijfers. Retrieved from: http://statline.cbs.nl/Statweb/publication/?DM=SLNL\&PA=37296NED\&D1=27$28 \& \mathrm{D} 2=49,1 \& \mathrm{VW}=\mathrm{T}$

Statistics Netherlands (2016). Begrippen: Allochtoon. Retrieved from: https://www.cbs.n1/nl-nl/onzediensten/methoden/begrippen\#id=allochtoon

Tammaru, T., \& Kontuly, T. (2011). Selectivity and destinations of ethnic minorities leaving the main gateway cities of Estonia. Population, Space and Place, 17 (5), 674-688.

Tammaru, T., Marcińczak, S., Van Ham, M., \& Musterd, S. (Eds) (2016). Socio-Economic Segregation in European Capital Cities: East Meets West. Oxford: Routledge.

Tunstall, R. (2016). Are neighbourhoods dynamic or are they slothful? The limited prevalence and extent of change in neighbourhood socio-economic status, and its implications for regeneration policy. Urban Geography, 37 (5), 769-784.

Van Ham M., \& Feijten P.M. (2008). Who wants to leave the neighbourhood? The effect of being different from the neighbourhood population on wishes to move. Environment and Planning A 40 (5), 1151-1170.

Van Ham, M, \& Tammaru, T. (2016) New perspectives on ethnic segregation over time and space. A domains approach. Urban Geography, DOI:10.1080/02723638.2016.1142152.

Van Gent, W.P.C. (2013). Neo-liberalization, housing institutions and variegatedgGentrification: How the 'third wave' broke in Amsterdam. International Journal of Urban and Regional Research, 37, 503-522.

Van Kempen, R., \& Priemus, H. (2002). Revolution in social housing in the Netherlands: Possible effects of new housing policies. Urban Studies, 39 (2), 247-253.

Vertovec, S. (2007). Super-diversity and its implications. Ethnic and Racial Studies, 30 (6), 10241054.

Yang, C. (2006). Evaluating latent class analyses in qualitative phenotype identification. Computational Statistics and Data Analysis, 50, 1090-1104.

Zwiers, M.D., Kleinhans, R.J., \& Van Ham, M. (2016). The path-dependency of low-income neighbourhood trajectories: An approach for analysing neighbourhood change, Applied Spatial Analysis and Policy, DOI: 10.1007/s12061-016-9189-z. 
Table 1 Maximum Likelihood Estimates for a Zero Inflated Poisson Latent Class Growth Model

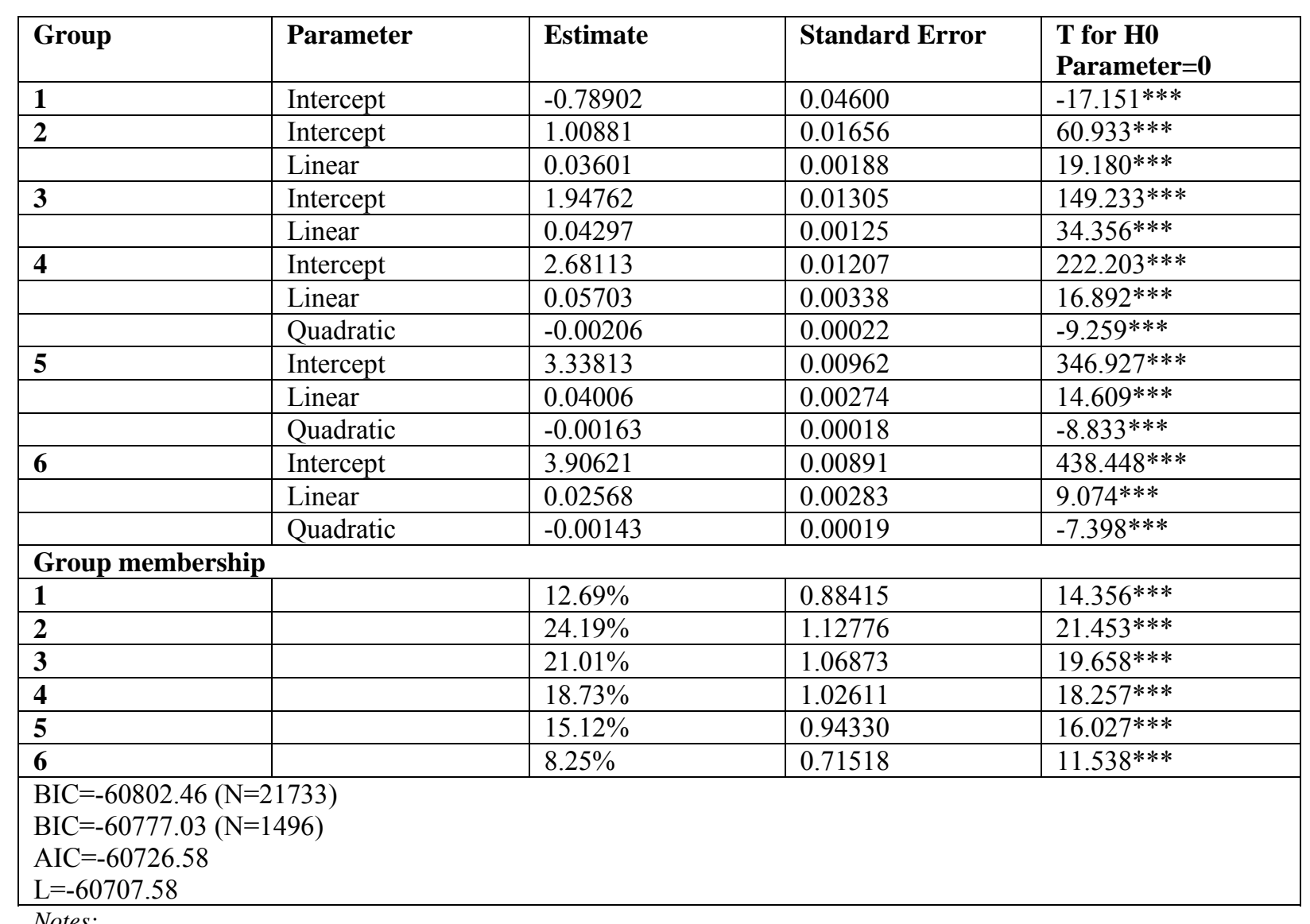

$\dagger \mathrm{p}<.10, * \mathrm{p}<.05, * * \mathrm{p}<.01, * * * \mathrm{p}<.001$ 
Fig. 1 Trajectory plot of the six groups

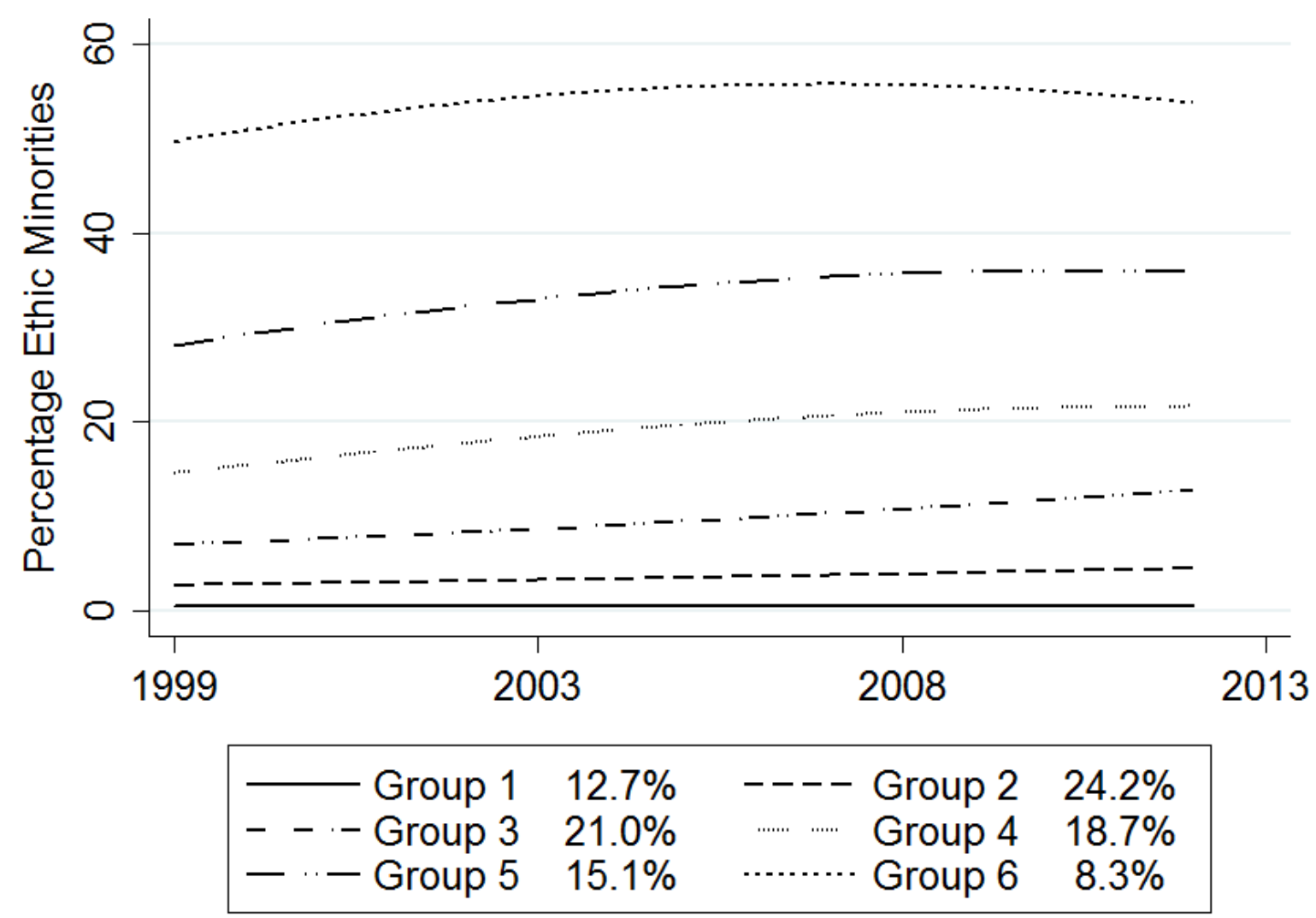


Table 2 Characteristics of the six trajectory groups in 2013

\begin{tabular}{|l|l|l|l|l|l|l|}
\hline & Group 1 & Group 2 & Group 3 & Group 4 & Group 5 & Group 6 \\
\hline $\begin{array}{l}\text { Average \% } \\
\text { Moroccans }\end{array}$ & $0.07 \%(0.26)$ & $0.83 \%(1.31)$ & $2.95 \%(2.98)$ & $6.02 \%(4.29)$ & $\begin{array}{l}11.69 \% \\
(7.60)\end{array}$ & $\begin{array}{l}19.25 \% \\
(13.51)\end{array}$ \\
\hline $\begin{array}{l}\text { Average \% } \\
\text { Turks }\end{array}$ & $0.06 \%(0.20)$ & $0.75 \%(0.95)$ & $2.52 \%(2.10)$ & $4.97 \%(3.12)$ & $8.70 \%(5.74)$ & $\begin{array}{l}15.34 \% \\
(9.53)\end{array}$ \\
\hline $\begin{array}{l}\text { Average \% } \\
\text { Surinamese }\end{array}$ & $0.39 \%(1.27)$ & $2.03 \%(1.80)$ & $4.92 \%(2.80)$ & $8.39 \%(4.30)$ & $\begin{array}{l}11.87 \% \\
(7.40)\end{array}$ & $\begin{array}{l}15.31 \% \\
(11.06)\end{array}$ \\
\hline $\begin{array}{l}\text { Average \% } \\
\text { Antillian }\end{array}$ & $0.11 \%(0.26)$ & $0.84 \%(0.90)$ & $1.63 \%(1.69)$ & $2.46 \%(2.48)$ & $3.77 \%(3.58)$ & $4.04 \%(4.01)$ \\
\hline $\begin{array}{l}\text { Average \% } \\
\text { Dutch }\end{array}$ & $\begin{array}{l}82.73 \% \\
(15.88)\end{array}$ & $\begin{array}{l}74.85 \% \\
(10.73)\end{array}$ & $\begin{array}{l}67.93 \% \\
(10.21)\end{array}$ & $\begin{array}{l}56.77 \% \\
(8.64)\end{array}$ & $\begin{array}{l}39.67 \% \\
(9.65)\end{array}$ & $\begin{array}{l}21.90 \% \\
(8.89)\end{array}$ \\
\hline $\begin{array}{l}\text { Average \% } \\
\text { Households } \\
\text { at risk of } \\
\text { poverty }\end{array}$ & $\begin{array}{l}19.48 \% \\
(14.23)\end{array}$ & $(10.75)^{1}$ & $\begin{array}{l}25.78 \% \\
(11.71)\end{array}$ & $\begin{array}{l}31.42 \% \\
(12.60)\end{array}$ & $\begin{array}{l}39.83 \% \\
(11.01)^{2}\end{array}$ & $\begin{array}{l}44.51 \% \\
(8.99)^{3}\end{array}$ \\
\hline $\begin{array}{l}\text { Average } \\
\text { income in } \\
\text { euros }\end{array}$ & $\begin{array}{l}73,202.08 \\
(30,920.32)\end{array}$ & $\begin{array}{l}64,758.90 \\
(26,616.54)^{\mathrm{a}}\end{array}$ & $\begin{array}{l}52,575.42 \\
(18,363.46)\end{array}$ & $\begin{array}{l}45,212.27 \\
(19,520.22)\end{array}$ & $\begin{array}{l}35,938.33 \\
(10,075.77)^{\mathrm{b}}\end{array}$ & $\begin{array}{l}31,036.53 \\
(6127.47)^{\mathrm{c}}\end{array}$ \\
\hline $\begin{array}{l}\text { Average } \\
\text { housing } \\
\text { values in } \\
\text { euros }\end{array}$ & $\begin{array}{l}502,698.9 \\
(228,955.2)^{\mathrm{d}}\end{array}$ & $\begin{array}{l}328,369.1 \\
(163,009.2)^{\mathrm{e}}\end{array}$ & $\begin{array}{l}235,567.3 \\
(97,287.58)^{\mathrm{f}}\end{array}$ & $\begin{array}{l}198,795.1 \\
(79,145.46)\end{array}$ & $\begin{array}{l}160,016.4 \\
(54,167.72)^{\mathrm{g}}\end{array}$ & $\begin{array}{l}139,770.3 \\
(35,936.88)^{\mathrm{c}}\end{array}$ \\
\hline $\mathbf{N}$ & & & & & & 227 \\
\hline
\end{tabular}

Notes: Standard deviations in parentheses

${ }^{a} \mathrm{~N}=360^{\mathrm{b}} \mathrm{N}=226^{\mathrm{c}} \mathrm{N}=122^{\mathrm{d}} \mathrm{N}=182^{\mathrm{e}} \mathrm{N}=355^{\mathrm{f}} \mathrm{N}=309^{\mathrm{g}} \mathrm{N}=225$ 
Fig. 2. Mean ethnic' net migration rates by trajectory group

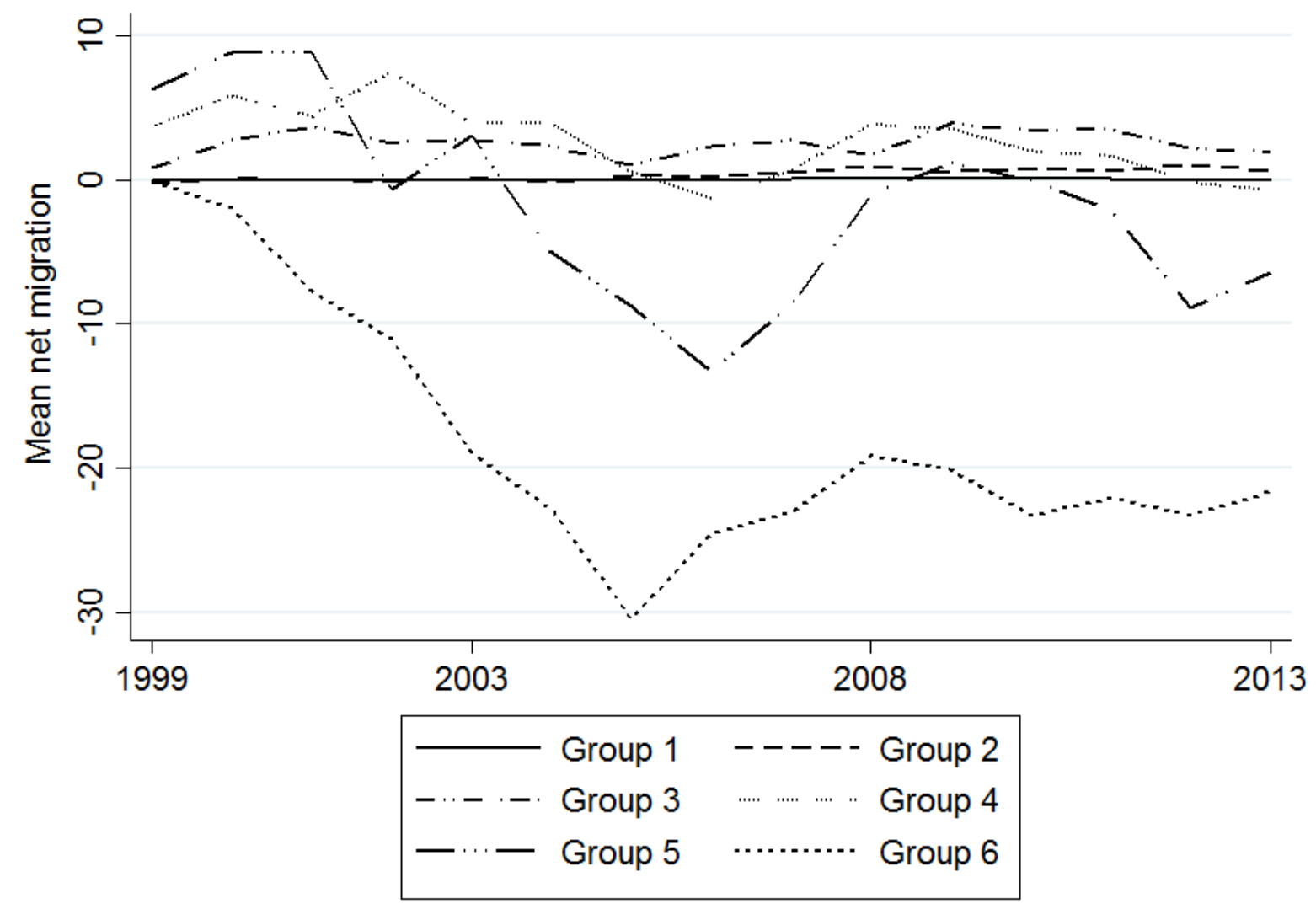


Fig. 3 Mean ethnic natural change by trajectory group

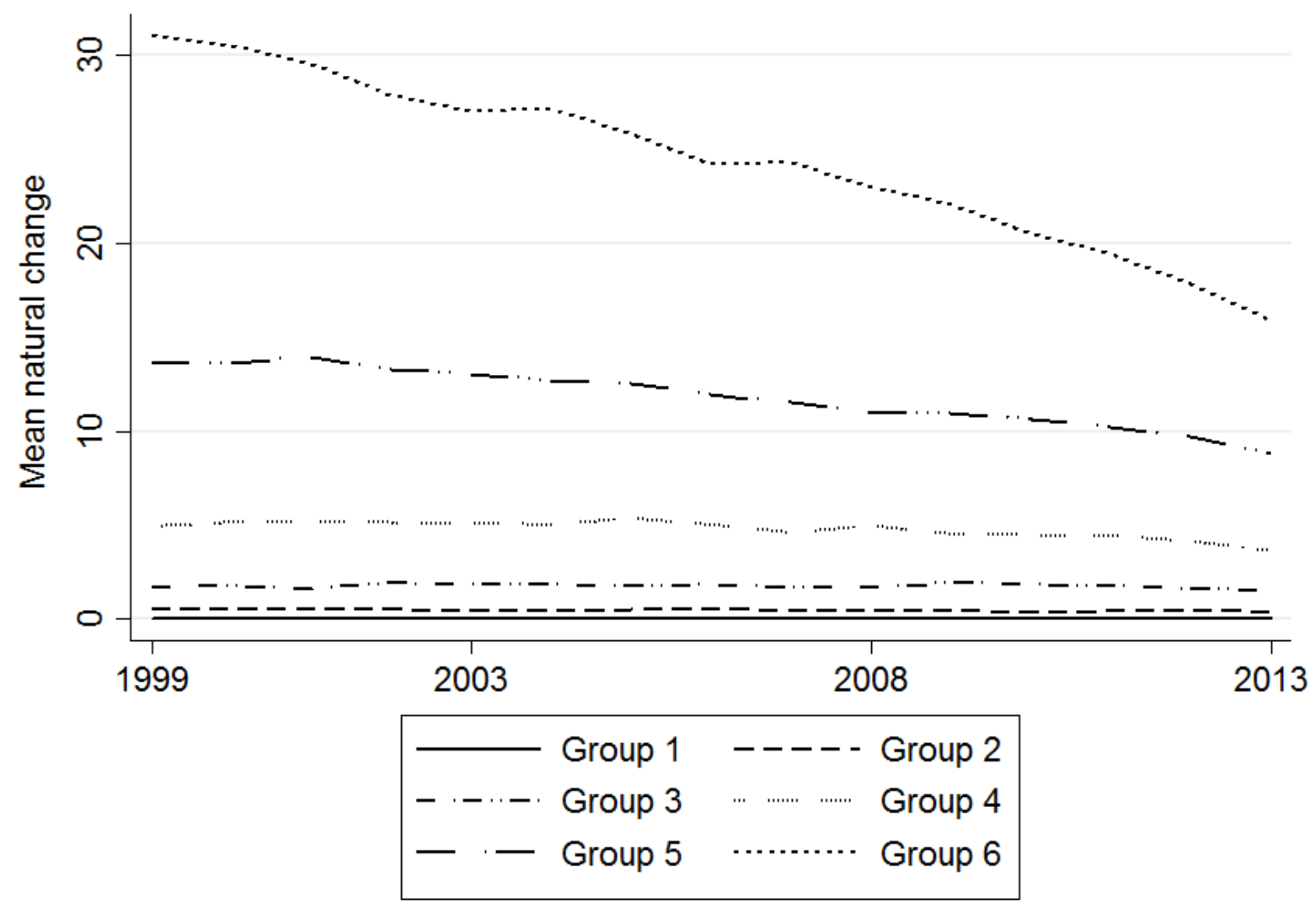


Fig. 4 Spatial distribution of the trajectory groups in Amsterdam

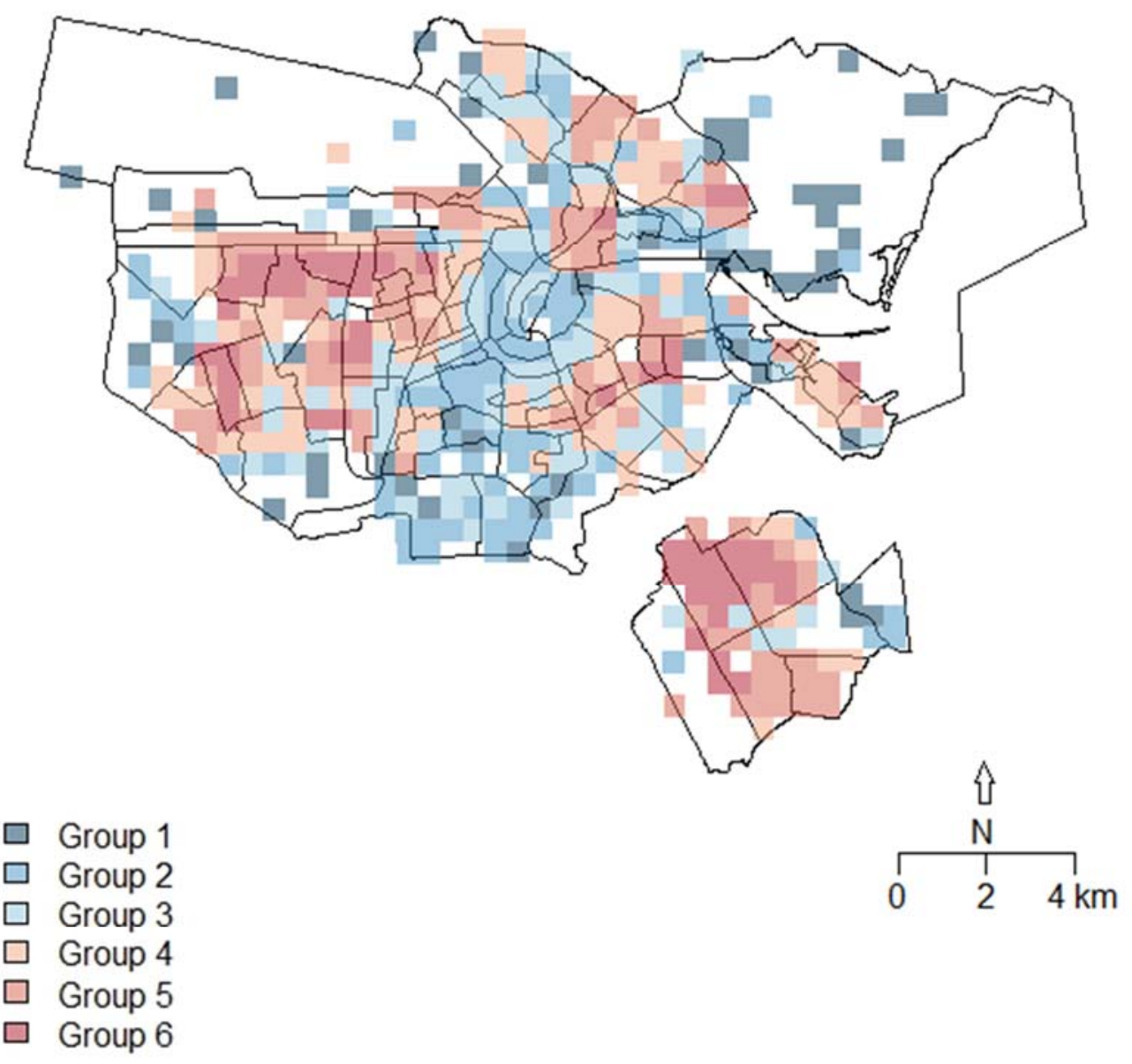


Fig. 5 Spatial distribution of the trajectory groups in Utrecht

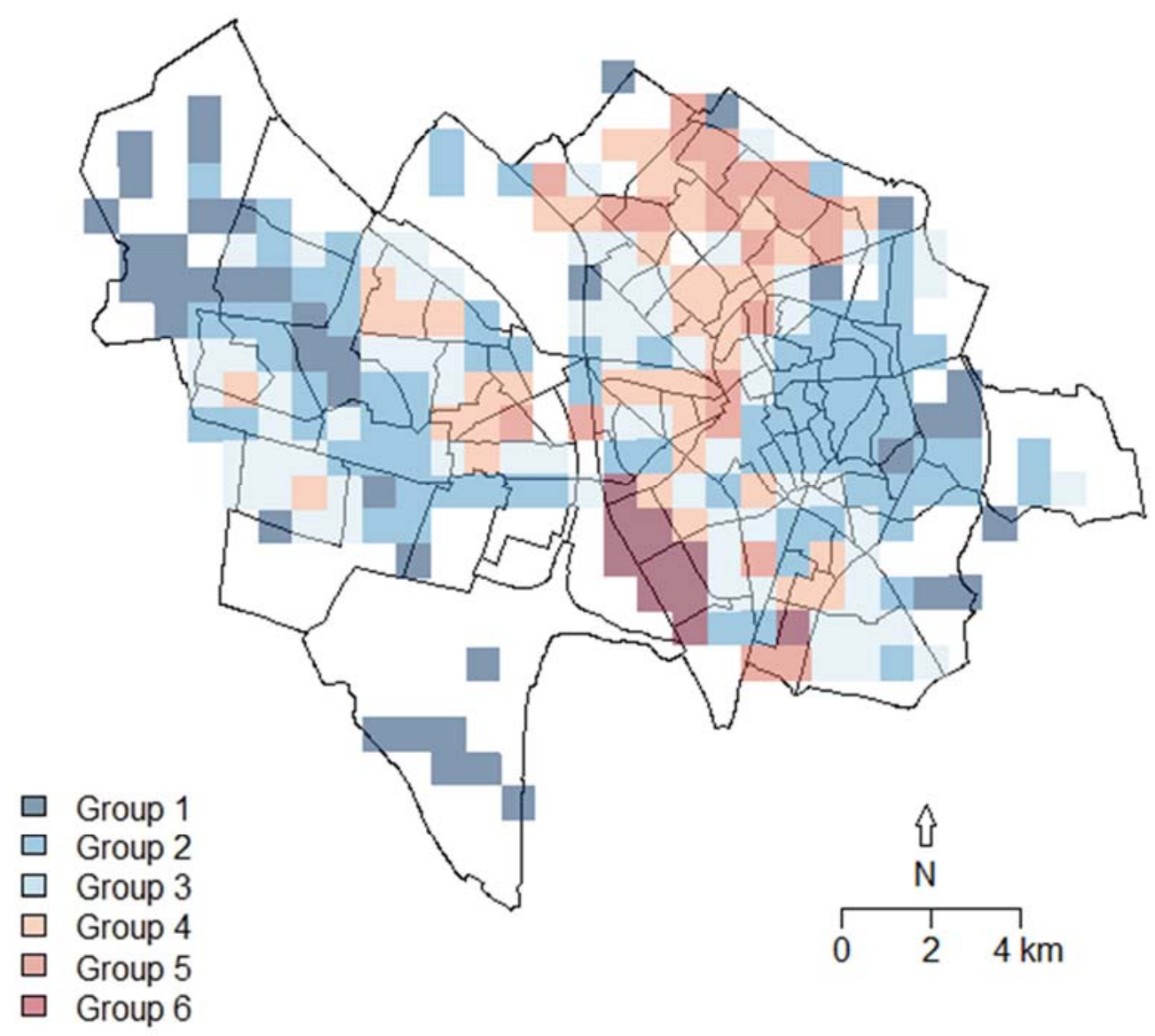


Fig. 6 Spatial distribution of the trajectory groups in the Hague

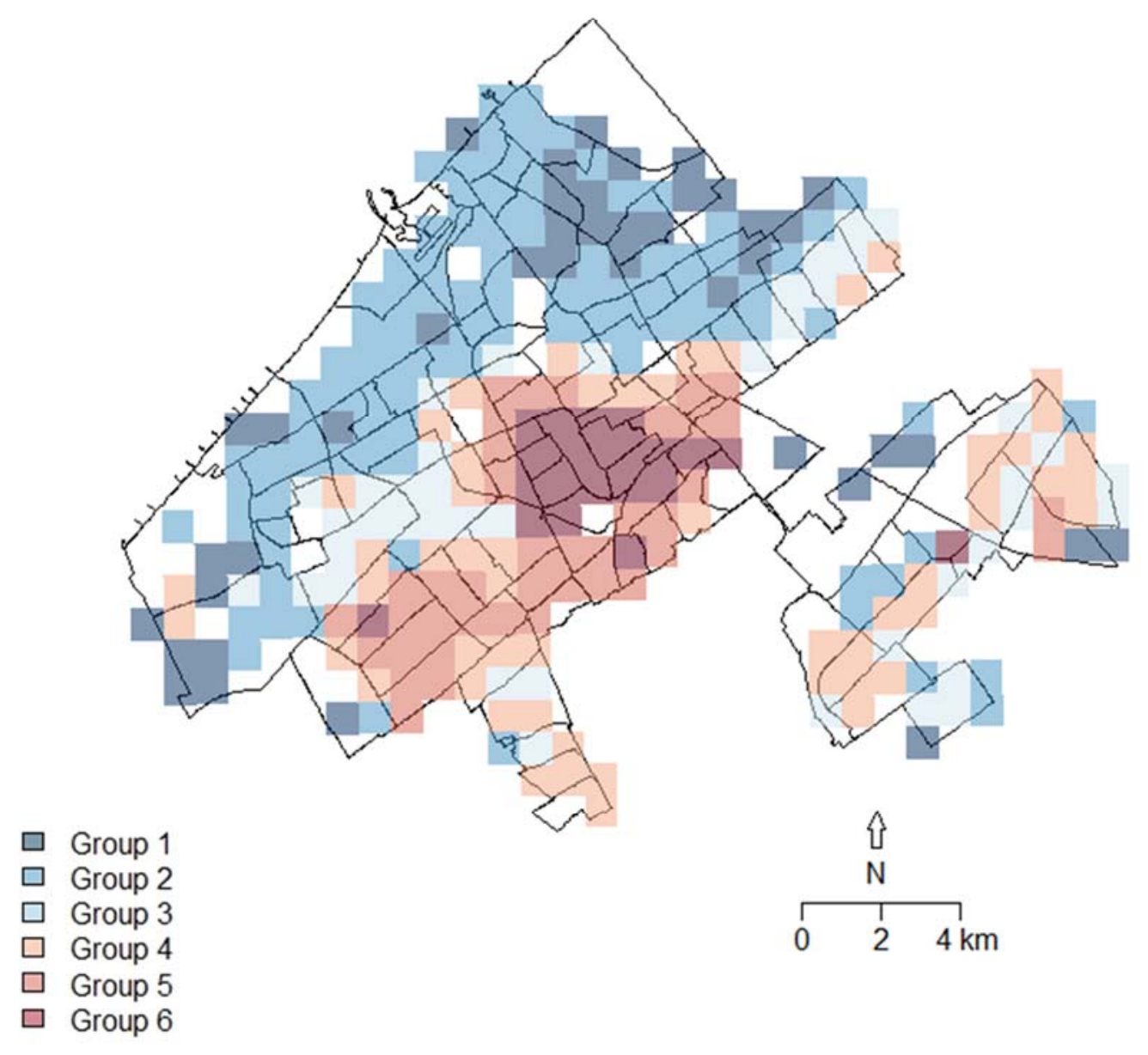


Fig. 7 Spatial distribution of the trajectory groups in Rotterdam

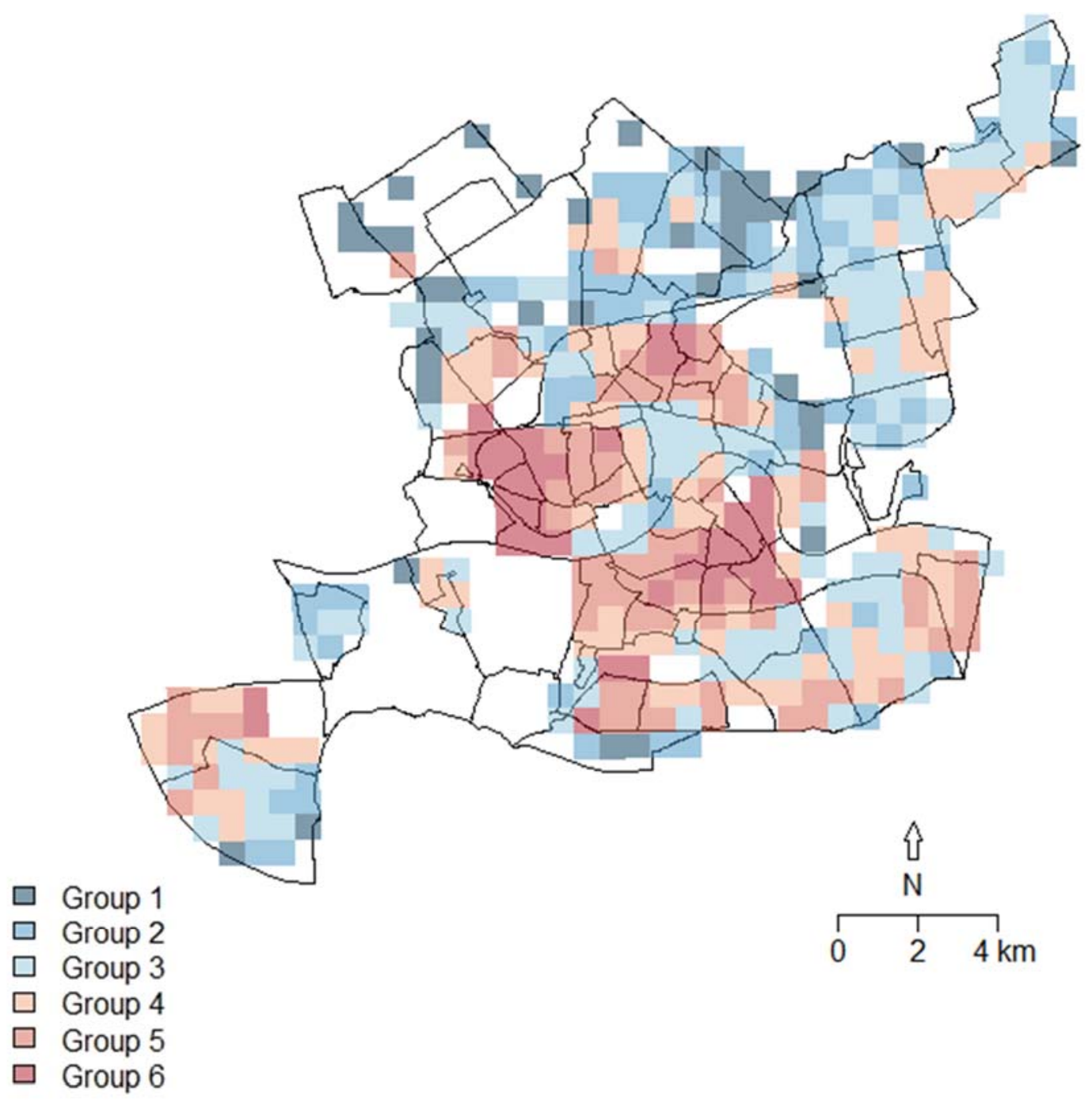


Table 3 Getis-Ord Gi* for each city

\begin{tabular}{|l|l|l|l|}
\hline & Observed value & Expected value & Z-score \\
\hline Amsterdam & 0.128434 & 0.118259 & $6.002680^{* * *}$ \\
\hline The Hague & 0.038465 & 0.030740 & $14.181250^{* * *}$ \\
\hline Rotterdam & 0.039639 & 0.032996 & $15.656473^{* * *}$ \\
\hline Utrecht & 0.043038 & 0.036340 & $9.254026^{* * *}$ \\
\hline
\end{tabular}

Notes:

$\dagger \mathrm{p}<.10,{ }^{*} \mathrm{p}<.05, * * \mathrm{p}<.01, * * * \mathrm{p}<.001$ 


\section{Appendix}

Table 4 Average posterior probabilities of group assignment and Bayesian Information Criterion (BIC) statistics of model fit

\begin{tabular}{|l|l|l|l|l|l|l|l|l|l|l|}
\hline & Group 1 & Group 2 & Group 3 & Group 4 & Group 5 & Group 6 & Group 7 & Group 8 & $\begin{array}{l}\text { BIC } \\
\text { (N=21733) }\end{array}$ & $\begin{array}{l}\text { BIC } \\
\text { (N=1496) }\end{array}$ \\
\hline 3 groups & 0.998 & 0.997 & 0.996 & & & & & & -76889.38 & -76878.68 \\
\hline 4 groups & 0.997 & 0.994 & 0.994 & 0.997 & & & & & -68143.06 & -68128.34 \\
\hline 5 groups & 0.992 & 0.992 & 0.991 & 0.995 & 0.998 & & & & -63393.19 & -63374.46 \\
\hline 6 groups & $\mathbf{0 . 9 9 6}$ & $\mathbf{0 . 9 8 6}$ & $\mathbf{0 . 9 8 2}$ & $\mathbf{0 . 9 9 2}$ & $\mathbf{0 . 9 9 2}$ & $\mathbf{0 . 9 9 6}$ & & & $-\mathbf{6 0 8 2 8 . 6 0}$ & $\mathbf{- 6 0 8 0 5 . 8 6}$ \\
\hline 7 groups & 0.989 & 0.997 & 0.979 & 0.983 & 0.974 & 0.992 & 0.990 & & -59184.62 & -59157.86 \\
\hline 8 groups & 0.982 & 0.988 & 0.966 & 0.967 & 0.983 & 0.979 & 0.989 & 0.996 & -58147.67 & -58116.89 \\
\hline
\end{tabular}

